\title{
A209 SERUM LEVELS OF IFN- $\alpha$ DO NOT CORRELATE WITH DISEASE ACTIVITY IN PATIENTS WITH DERMATOMYOSITIS/POLYMYOSITIS
}

Vencovský J,1 Król P, Kryštůfková 0,1 Polanská P, ${ }^{1}$ Mann $H_{1}^{1}$ Klein M, Beran $0^{3,4}$ ${ }^{1}$ Institute of Rheumatology, First Faculty of Medicine, Charles University, Prague, Czech Republic, ${ }^{2}$ Department of Paediatrics and Adolescent Medicine, First Faculty of Medicine and General Teaching Hospital, Charles University, Prague, Czech Republic, ${ }^{3}$ Department of Infectious and Tropical Diseases, First Faculty of Medicine, Charles University, Prague; ${ }^{4}$ University Hospital Bulovka, Prague, Czech Republic

10.1136/ard.2010.149021.19

Introduction Recent studies show an important role of type I interferon (IFN) in the proinflammatory process leading to disease manifestations in muscle tissue in patients with polymyositis (PM) and dermatomyositis (DM).

Aim To investigate the relationship of soluble IFN- $\alpha$ serum levels with clinical and laboratory characteristics in patients with PM and DM.

Methods Serum samples of 43 patients with DM ( $n=24)$ and PM ( $\mathrm{n}=19)$ (32 females/11 males) were selected from a cohort of $81 \mathrm{PM} / \mathrm{DM}$ cases with the preference for those with anti-Jo-1 antibodies $(n=26)$ and those with muscle MRI performed $(n=22)$. IFN- $\alpha$ levels were measured using beadbased assay (human IFN- $\alpha$ FlowCytomix Simplex, Bender MedSystems, sensitivity $2.2 \mathrm{pg} / \mathrm{ml}$ ). Clinical activities were assessed using the MYOACT tool. Degree of muscle oedema on STIR muscle MRI was used to measure local disease activity and evaluated using $10 \mathrm{~cm}$ visual analogue scale. Patients were either untreated $(n=19)$, treated with prednisone at doses $\leq 20 \mathrm{mg}(\mathrm{n}=15)$, or $>20 \mathrm{mg}$ per day $(\mathrm{n}=9)$ at the time of blood collection. Healthy subjects $(n=25)$ and patients with viral infection $(n=6)$ were used as controls.

Results Significantly lower levels of IFN- $\alpha$ were found in sera of myositis patients in comparison with controls. No difference was noted between patients who were untreated, or treated with low or high prednisone. IFN- $\alpha$ levels were significantly higher in anti-Jo-1 positive patients (median 117.8 
$\mathrm{pg} / \mathrm{ml}$, range $70-378)$ in comparison with anti-Jo1 negative (median $93.4 \mathrm{pg} / \mathrm{ml}$, range $0-199)(\mathrm{p}=0.05)$. There were no significant differences in IFN- $\alpha$ levels between PM and DM patients. Significant negative correlation was found between IFN- $\alpha$ and the intensity of MRI signal. None of the clinical or laboratory parameters as assessed by MYOACT showed any correlation with IFN- $\alpha$ levels, with the exception of the tendency to higher IFN- $\alpha$ levels $(p=0.064)$ in the presence of interstitial lung disease.

Conclusion Serum levels of IFN- $\alpha$ in patients with PM and DM were lower compared to controls. This is not a consequence of the treatment since the levels of IFN- $\alpha$ were not different in patients tested before or during therapy. Serum levels of IFN- $\alpha$ do not seem to be an indicator of clinical activity; the lower the serum level the more severe the muscle oedema, as demonstrated by the intensity parameter on MRI. This could indicate rather local than systemic effect of IFN- $\alpha$. Alternatively, other type I interferons and not the IFN- $\alpha$ may be responsible for the type I IFN signature that is characteristic for many DM and PM patients. 